\title{
Full life-cycle assessment of gene flow consistent with fitness differences in transgenic and wild-type Japanese medaka fish (Oryzias latipes)
}

\author{
Kelly M. Pennington ${ }^{1 *}$, Anne R. KAPUscinskI ${ }^{2,3}$, Michael S. MORTON ${ }^{2}$, Anne M. CoOPER ${ }^{1}$ and Loren M. MILleR ${ }^{2}$ \\ 1 Conservation Biology Graduate Program, University of Minnesota, St. Paul, MN, USA \\ 2 Department of Fisheries, Wildlife, and Conservation Biology, University of Minnesota, St. Paul, MN, USA \\ 3 Current address: Environmental Studies Program, Dartmouth College, Hanover, NH, USA
}

Transgenic fish in development for aquaculture could escape from farms and interbreed with wild relatives in the nearby environment. Predicting whether escapes would result in transgene introgression is a major challenge in assessing environmental risks of transgenic fish. Previous studies have simulated gene flow from transgenic fish using mathematical modeling of fitness traits to predict the relative selective value of transgenic genotypes. Here, we present the first study of gene flow over the full life cycle in openly-breeding populations of transgenic animals, along with measurement of fitness traits. We conducted two invasion experiments in which we released two lines of growth-enhanced transgenic fish (T67 and T400), Japanese medaka (Oryzias latipes), into populations of wild-type (W) medaka in structured mesocosms. After several generations, the frequency of transgenic fish varied across replicates in the first invasion experiment ( 6 months), but the frequency of transgenic fish decreased in the second experiment (19 months). We also measured selected fitness traits in transgenic and wild-type medaka because these traits could be used to predict the relative selective value of a genotype. We found that: T400 males were more fertile than W males; offspring of W females lived longer than those with transgenic mothers; and W and T67 females reached sexual maturity sooner than T400 females. In contrast with other research that reported larger transgenic males had a mating advantage, we found that W males obtained more matings with females than $T$ males; genetic background effects may account for our differing results as we compared $\mathrm{W}$ and $\mathrm{T}$ fish derived from different strains. The decreasing frequency of transgenic fish in the second invasion experiment suggests that transgenic fish had a selective disadvantage in the experimental environment. Our finding of transgenic advantage of some fitness traits and wild-type advantage in others is consistent with our invasion experiment results.

Keywords: Oryzias latipes / medaka fish / risk assessment / gene flow / relative fitness / genetically modified / transgenic / mesocosm

\section{INTRODUCTION}

Farmed fish are known to escape from farms in large numbers and with a high frequency, and to hybridize with wild fish (National Research Council, 2004). Gene flow from escaped farmed salmon to wild salmon populations has been shown to depress fitness, which can reduce local adaptation and productivity and, under continual gene flow, prevent re-adaptation of the wild population (Hindar et al., 1991; McGinnity et al., 2003; Naylor et al., 2005). Such gene flow can lead to rapid genetic homogenization between the farmed and wild populations, reducing the long-term ability of wild populations to adapt to environmental change (Fleming et al., 2000; Hindar et al.,

*Corresponding author: kmp@umn.edu
1991). In addition, the expression of novel phenotypes by transgenic fish could result in different fitness-related traits compared to wild relatives, with population-wide consequences. In the case of growth-enhanced transgenic fish, the effect of mechanisms like resource competition might be amplified by the higher feeding motivation of faster-growing fish (Johnsson et al., 1996; Jonsson et al., 1996; Sundström et al., 2003). Farmed transgenic fish are expected to escape from aquaculture systems and interbreed with wild relatives, unless they are raised under adequate physical and biological confinement (National Research Council, 2004).

Predicting gene flow from escaped transgenic fish to a wild population is a major need in environmental risk assessment of transgenic fish (Devlin et al., 2006; 


\section{K.M. Pennington et al.}

Kapuscinski et al., 2007; National Research Council, 2008). This is not only a gap in the science, but a policy-relevant one: growth-enhanced transgenic Atlantic salmon (Salmo salar) developed for large-scale aquaculture are currently under regulatory review in the USA (Aqua Bounty Technologies, 2010; Food and Drug Administration, 2010; National Research Council, 2002). Life-history traits affecting fitness can be used to predict the potential invasiveness of a species (e.g., Sakai et al., 2001), though correlations between more invasive fish species and life history characteristics favoring a fitness advantage are only recently being tested (Vila-Gispert et al., 2005). Laboratory studies have found that growthenhanced transgenic fish and their unmodified relatives can have different values for some primary components of total fitness, such as increased male mating advantage (Howard et al., 2004), increased female fecundity (Bessey et al., 2004), and reduced juvenile viability, in transgenic individuals (Muir and Howard, 2001). A few studies have considered the possible results of an invasion of transgenic fish, based on relative hypothetical or experimentally-measured values of selected fitnessrelated traits such as viability, fecundity, and male mating advantage (Hedrick, 2001; Muir and Howard, 1999, 2001). However, these studies have so far only simulated a transgene invasion with deterministic models. No studies we are aware of have undertaken the fulllife-cycle assessment of transgenic animals in openlybreeding populations, in which reproductive and viability aspects of fitness impact more than one generation, such as we present here.

We used Japanese medaka fish (Oryzias latipes) in our study. Medaka are well-suited to population biology research (Yamamoto, 1975) and can live and reproduce well in laboratory conditions. Medaka are small (usually less than $4 \mathrm{~cm}$ in length), and have a generation time of about two months; both factors that enabled us to carry out multi-generational population experiments in a confined laboratory environment. Given the right conditions, medaka can mate daily for an extended period of time. Reproductive activity usually takes place within an hour of daybreak, or as simulated by the beginning of the photoperiod in captivity (Shima and Mitani, 2004; Wittbrodt et al., 2002).

In addition to being a useful model for population genetics research, medaka have proven to be relatively easy to genetically engineer; in fact, one of the first reports of stable trangenesis in fish used medaka (Ozato et al., 1986). We used two lines (MtsGH-67 and MtsGH-400; hereafter T67 and T400, respectively) of growth-enhanced transgenic medaka (produced by William Muir, Purdue University). The T67 and T400 fish were engineered with an all-salmonid gene construct (Devlin et al., 1994) consisting of a metallothionein-B promoter (Chan and Devlin, 1993) and sockeye salmon full-length, type-1 growth hormone gene (Devlin, 1993). The transgenic fish were derived from founder medaka that the Muir lab obtained from Japan (Jiménez, 2000) and subsequently backcrossed (Kruer et al., 2002). We used a line of wild-type medaka (hereafter W) descended from wild fish captured in Japan (obtained from Pacific Aquatics, Chatsworth, CA, USA), but not from the same population of fish used to initially produce the T67 and T400 lines.

Our objective was to test whether the relative fitness of transgenic fish could provide useful information about the outcome of an invasion of transgenic fish into a wildtype population. In a confined laboratory environment, we carried out two types of experiments using medaka: (1) invasion experiments, in which large populations of W medaka were "invaded" by transgenic medaka; and (2) fitness trait measurements, in which we compared the fecundity, fertility, mating advantage, juvenile viability, age at sexual maturity, and longevity of W, T67 and T400 medaka. We controlled a number of key environmental conditions across all experiments, including water temperature, feeding regime, water source, and photoperiod.

\section{RESULTS}

\section{Characterization of transgenic lines}

We confirmed expression of the transgene in T67 and T400 medaka. We also monitored size in groups of fish of each genotype (Fig. 1). Initially, at seven weeks of age, T67 fish were significantly larger than both T400 and W fish (Tukey HSD, adj. $p=0.007$ and 0.047 , respectively). At eight and nine weeks of age, T67 fish were larger than T400 fish (Tukey HSD, adj. $p<0.032$ ). Ten- and 11-week-old fish were not significantly different in weight between genotypes. Twelve-week-old $\mathrm{W}$ fish were significantly larger than T400 fish (Tukey HSD, adj. $p=0.029$ ). There were no significant differences between genotypes at 13,14 , or 16 weeks of age, but at 15 and 17 weeks of age $\mathrm{W}$ fish had a weight advantage over T400 fish (Tukey HSD, adj. $p<0.047$ ).

\section{Invasion experiments}

We carried out the invasion experiments using nine mesocosms, large fiberglass tanks with habitat structure. All mesocosms were stocked with large numbers of wildtype medaka. Three mesocosms were invaded by T67 medaka, three by T400 medaka, and three were maintained as control (W only) populations (Tab. 1). We repeated invasion experiments twice: invasion experiment I 


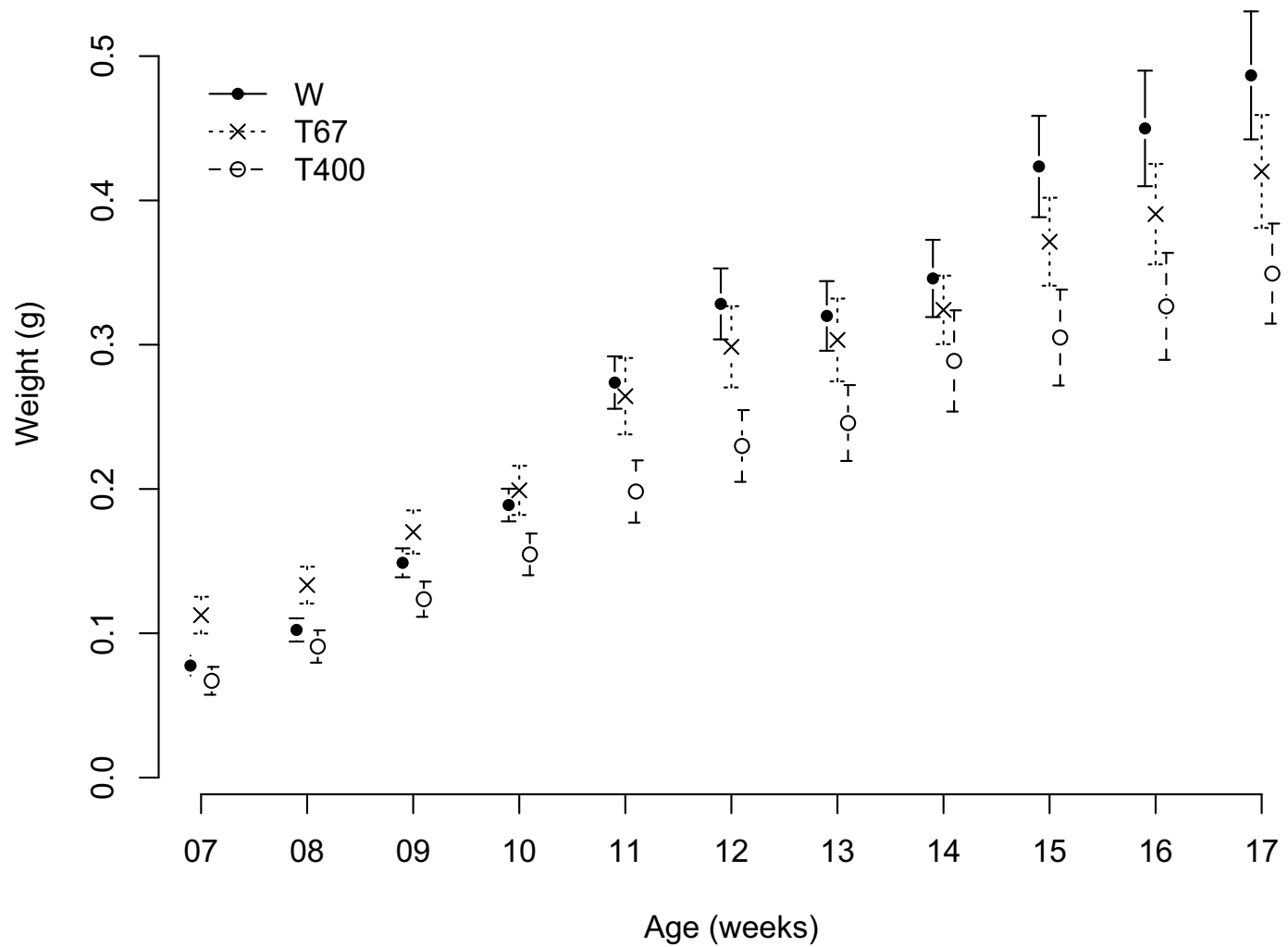

Figure 1. Weight of fish of each genotype over ten weeks.

Table 1. Design of invasion experiments.

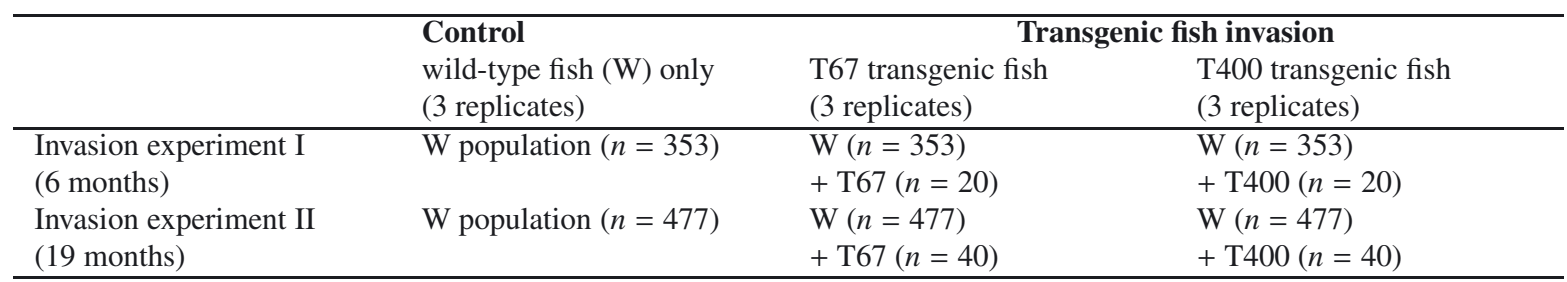

was six months in duration; invasion experiment II lasted for 19 months.

In invasion experiment I, the final frequency of transgenic fish varied across replicates, ranging from disappearance of transgenic fish in three of the mesocosms and a decreased frequency of transgenic fish in one mesocosm, to an increase in two of the T400 mesocosms (Tab. 2; sign test, $p=0.344$ ). In experiment II, we detected at least one transgenic fish in both T400 and T67 treatment mesocosms after 12 months. However, by the end of the experiment at 19 months, we found no transgenic fish in five mesocosms and only one T67 transgenic fish remained in the sixth (Tab. 2); a significant decrease in the proportion of transgenic fish in experiment II (sign test, $p=0.016$ ).
Reproduction and recruitment occurred in all mesocosms in both experiments. We observed eggs and fry in all mesocosms daily after the second week of both experiments. Furthermore, in one of the mesocosms in which the proportion of transgenic fish increased in experiment I, at least two T400 fish at the end of the experiment were offspring, as they were 12 and $16 \mathrm{~mm}$ standard length - too small to have been introduced at the initiation of the experiment. In experiment II, interim sampling for the presence of transgenic fish revealed several transgenic fish too small to have been introduced at the beginning of the experiment, for example: five months after the initiation of experiment II, we found a T67 fish weighing less than $0.1 \mathrm{~g}$; nine months into the experiment we sampled two T67 females, weighing $0.133 \mathrm{~g}$ and $0.171 \mathrm{~g}$, 
K.M. Pennington et al.

Table 2. Initial and final frequencies of transgenic fish in invasion experiments I and II.

\begin{tabular}{llll}
\hline & Transgenic fish line & $\begin{array}{l}\text { Initial frequency } \\
\text { of transgenic fish }\end{array}$ & $\begin{array}{l}\text { Final frequency of transgenic fish } \\
\text { (transgenic fish/total fish) }\end{array}$ \\
\hline & T400 & 0.054 & $0.057(5 / 88)$ \\
& & 0.054 & 0 \\
Invasion experiment I & & 0.054 & $0.086(6 / 70)$ \\
(6 months) & T67 & 0.054 & 0 \\
& & 0.054 & 0 \\
& & 0.054 & $0.024(2 / 82)$ \\
\hline & T400 & 0.077 & 0 \\
Invasion experiment II & & 0.077 & 0 \\
(19 months) & & 0.077 & 0 \\
\cline { 2 - 4 } & $\mathrm{T} 67$ & 0.077 & $0.020(1 / 49)$ \\
& & 0.077 & 0 \\
\hline
\end{tabular}

from two different mesocosms; and one year into the experiment we detected a T400 male, $0.160 \mathrm{~g}$, and T400 female, $0.106 \mathrm{~g}$, in a T400 mesocosm. We noted a number of other individuals as probable offspring during the experiments and at their termination.

In both experiments, population sizes decreased in each mesocosm (Fig. 2), but multiple comparisons tests revealed no significant differences in mean final population size between control and experimental treatment populations (Tukey HSD, all $p>0.566$ ). Pathological tests on a sample of the deceased experimental fish indicate that the observed declines were caused by a Mycobacterium haemophilum infection (unpublished data, S. Robbe-Austerman, USDA-APHIS, National Veterinary Services Laboratories, Ames, IA).

\section{Fitness measurements}

We measured fitness traits on fish housed in glass aquaria. We measured fecundity and fertility on wild-type and transgenic fish paired in pure and reciprocal crosses. We tested T67 and T400 medaka with W fish in two trials each, resulting in a total of four trials. We used offspring from the fecundity and fertility experiments to measure age at sexual maturity, juvenile viability, and longevity. We tested the relative mating success of $\mathrm{W}$ males with each transgenic line separately, in five test periods for each T400 and T67 experiment.

\section{Fecundity}

Female genotype did not have a significant effect on total ten-day egg production, either in ANOVA models (Type II ANOVA, $F_{(2,63)}=1.976, p=0.147$ ) or multiple comparisons tests (Tukey HSD, all adj. $p>0.081$ ). T67 females produced an average of 214.4 eggs over ten days $( \pm 115.6 \mathrm{SD}, n=20)$; W females, $187.3( \pm 99.7$, $n=37)$; and T400 females, $151.5( \pm 92.9, n=15)$. The starting weight of females, a covariate in our model, was a significant predictor of ten-day egg production (Type II ANOVA, $F_{(1,63)}=4.371, p=0.041$ ); however, the relationship was negative (slope estimate $=-192.64$; Fig. 3). Transgenic females weighed significantly more than wild-type females at the start of all fecundity trials (Tukey HSD, T67-W and T400-W both adj. $p<$ 0.001 ). Overall, $\mathrm{T} 400$ females were largest (mean $\pm \mathrm{SD}$, $0.598 \pm 0.171 \mathrm{~g})$, followed by T67 $(0.554 \pm 0.109 \mathrm{~g})$ and $\mathrm{W}$ females $(0.417 \pm 0.100 \mathrm{~g})$.

\section{Fertility}

The observed fertility rate of all males was high: T400 males fertilized 0.986 ( \pm 0.019 SD) of intact eggs; W males, 0.983 ( $\pm 0.031 \mathrm{SD})$; and T67, $0.966( \pm 0.054)$. In a bootstrap simulation, T400 males were significantly more fertile than wild-type males (Tab. 3; 95\% Bootstrap CI with Bonferonni correction; W-T400: $-6.595,-0.280$ ). Like the females with which they were paired, transgenic males weighed significantly more than wild-type males at the start of fertility trials (Tukey HSD, T67-W and T400-W both adjusted $p<0.001$ ). Overall, T67 males were largest (mean $\pm \mathrm{SD}, 0.455 \pm 0.074 \mathrm{~g}$ ), followed by $\mathrm{T} 400(0.443 \pm 0.104 \mathrm{~g})$ and $\mathrm{W}$ males $(0.315 \pm 0.039 \mathrm{~g})$.

\section{Mating advantage}

In the T400 mating advantage experiments, $\mathrm{W}$ males obtained $53 \%$ of matings alone, and T400 males mated with the female alone $27 \%$ of the time. When we considered W matings as "successes" and T400 matings as "failures" in a binomial model, W males had a significant advantage 
Relative fitness of transgenic medaka fish consistent with gene flow

A
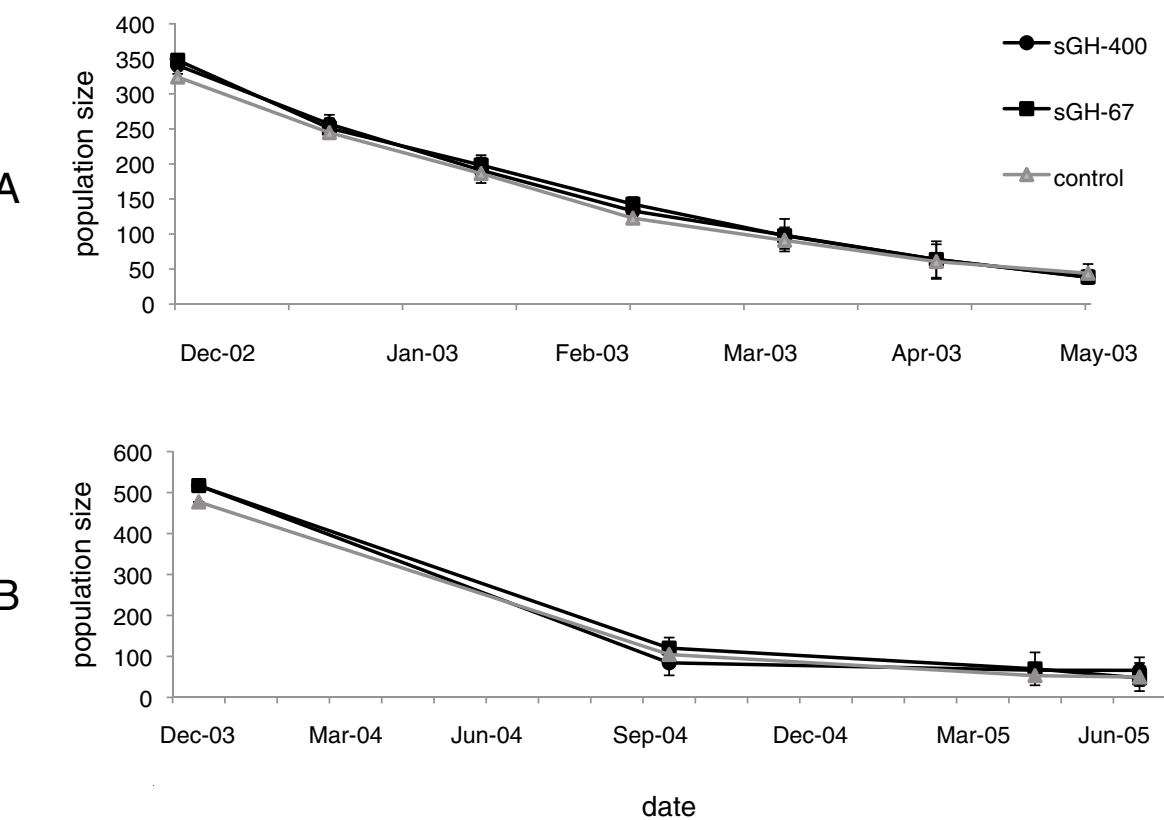

Figure 2. A: Declining population in invasion experiment I. Population sizes are estimates based on (original population size - mortalities to date), except May 2003 measurement, which is a census size. B: Population size during invasion experiment II. Population sizes were all determined via census. Error bars are \pm SD.

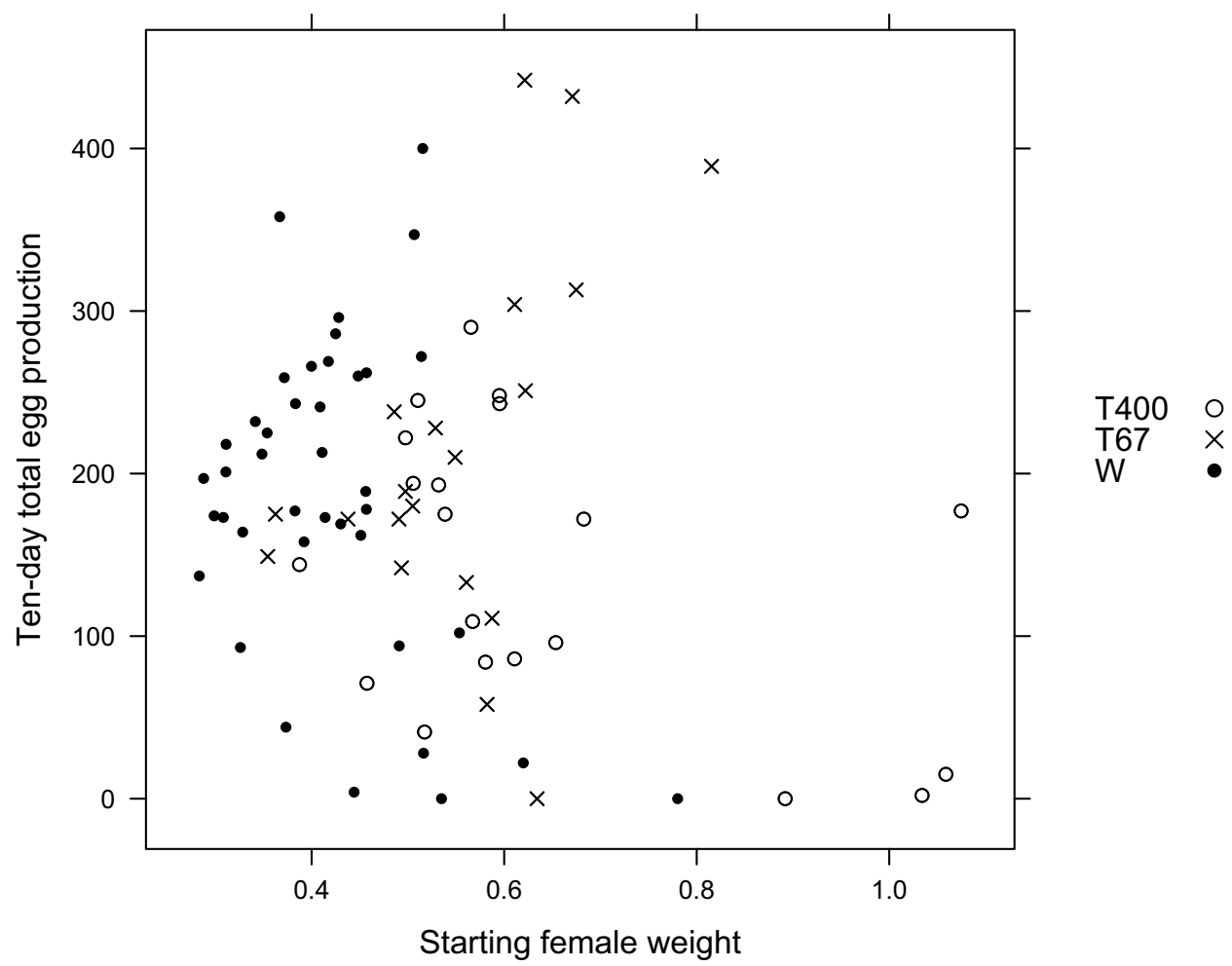

Figure 3. Relationship between female weight at the beginning of fecundity experiments and ten-day total egg production, by female genotype. 
Table 3. Bootstrap 95\% confidence intervals (with Bonferroni correction) for differences in male fertility by genotype. Bold numbers indicate significant differences.

\begin{tabular}{lll}
\hline Male genotype comparison & Lower bound & Upper bound \\
\hline Wild-type - T67 & -3.295 & 0.908 \\
T67 - T400 & -4.428 & 0.437 \\
Wild-type - T400 & $\mathbf{- 6 . 5 9 5}$ & $\mathbf{- 0 . 2 8 0}$ \\
\hline
\end{tabular}

(intercept $\left.=0.560, z_{(\mathrm{df}=19)}=2.187, p=0.029\right)$. The remaining $20 \%$ of the matings were trio matings, in which both the $\mathrm{W}$ and T400 male mated with the female in the same mating event, but we did not test the paternity of the fertilized eggs. In a model to simulate a case where all trio matings were assigned to the $\mathrm{W}$ male, the $\mathrm{W}$ advantage increased (intercept $=0.677, z_{(\mathrm{df}=22)}=3.121$, $p=0.002)$. At the other extreme, when we combined trio matings with T400 matings, W males retained a small, but not significant, advantage (intercept $=0.105$, $\left.z_{(\mathrm{df}=22)}=0.513, p=0.608\right)$. Before being included in the experiment, T400 males were an average of $0.404 \mathrm{~g}$ $( \pm 0.116 \mathrm{SD} ; n=12)$ and $\mathrm{W}$ males weighed $0.362 \mathrm{~g}$ $( \pm 0.110 \mathrm{SD} ; n=12)$; this difference was not significant $\left(t\right.$-test, $\left.t_{(\mathrm{df}=21.942)}=0.913, p=0.371\right)$. T400 males weighed, on average, $0.035 \mathrm{~g}$ more than the $\mathrm{W}$ males with which they were paired in the T400 experiments.

In the T67 mating advantage experiments, $45 \%$ of the matings were trio matings. $\mathrm{W}$ males obtained $37 \%$ of matings alone, while T67 males mated with the female alone $18 \%$ of the time. A binomial model in which W matings were successes and T67 matings were failures had a significant intercept term (intercept $=0.731$, $\left.z_{(\mathrm{df}=15)}=2.165, p=0.030\right)$. When all trio matings were assigned to the model with $\mathrm{W}$ successes, the $\mathrm{W}$ advantage increased dramatically (intercept $=1.460, z_{(\mathrm{df}=23)}=$ 4.744, $p<0.001)$. A model in which T67 and trio matings, together, were considered successes, and $\mathrm{W}$ matings were failures, was not significant (intercept $=0.442$, $\left.z_{(\mathrm{df}=23)}=1.791, p=0.073\right)$. At the beginning of the experiment, T67 males weighed an average $0.464 \mathrm{~g}$ $( \pm 0.057 \mathrm{SD} ; n=5)$ and $\mathrm{W}$ males weighed $0.433 \mathrm{~g}$ $( \pm 0.025 \mathrm{SD} ; n=5)$, not a significant size advantage $\left(t\right.$-test, $\left.t_{(\mathrm{df}=5.504)}=1.116, p=0.311\right)$. T67 males had an average weight advantage of 0.039 grams over the $\mathrm{W}$ males with which they were paired.

\section{Age at sexual maturity}

T67 females began to produce eggs at the earliest age (mean $\pm \mathrm{SD}, 48.760 \pm 6.809$ days; $n=25$ ), followed by $\mathrm{W}(51.684 \pm 6.225 ; n=28)$ and $\mathrm{T} 400(54.846 \pm 3.209$; $n=26$ ) fish. Multiple comparisons tests found that T67 and $\mathrm{W}$ females matured significantly sooner than $\mathrm{T} 400$ females (Tukey HSD; T67-T400 adj. $p<0.001$; W-T400 adj. $p=0.033$ ). However, in a linear model, the genotype of the individual sexually mature female was not a significant predictor of age at sexual maturity (Type II ANOVA, $\left.F_{(2,75)}=0.055, p=0.946\right)$. T67 fish weighed an average of $0.222 \mathrm{~g}( \pm 0.058 \mathrm{SD}, n=25)$ while $\mathrm{W}$ females were $0.195 \mathrm{~g} \mathrm{(} \pm 0.043 \mathrm{SD}, n=15)$ at sexual maturity; not a significant difference $\left(t\right.$-test, $t_{(\mathrm{df}=36.112)}=-1.666$, $p=0.104)$.

\section{Juvenile viability}

In trial 1 , we observed $70 \%$ survival to sexual maturity among fry from two T400 parents, compared to $94 \%$ among offspring of two $\mathrm{W}$ parents and $98 \%$ among offspring of one W and one T400 parent. We found differences between observed and expected values across the four parental crosses in trial $1\left(\chi_{(\mathrm{df}=3)}^{2}=30.220\right.$, $p<0.001)$. We excluded data for trial 2 from analysis because we made errors stocking fry in that trial.

In trial 3, we observed $79 \%$ survival to sexual maturity across all parental crosses. We observed and genotyped the following number of mortalities from each parental cross: six among offspring of two $\mathrm{W}$ parents (all W offspring); eight among offspring of T67 males and $\mathrm{W}$ females (all T67 fish); 12 among offspring of two T67 fish (all T67 offspring); and 16 among offspring of a $\mathrm{W}$ female and T67 male (15 T67 offspring and one W). However, observed and expected proportions of fry surviving to sexual maturity did not differ by parental cross in trial $3\left(\chi_{(\mathrm{df}=3)}^{2}=7.110, p=0.069\right)$. Most fish in trial 3 died at about the same time ( $22 \pm 6.967$ days), regardless of parentage. We did not detect any deceased fish before sexual maturity in trial 4.

\section{Longevity}

The medaka in our experiments lived on average to over a year old (382 \pm 178 days). We were able to identify 57 of the mortalities as T67 fish, 103 as T400, and 208 as W fish (Tab. 4). In the model to predict longevity of adult fish, parental cross was significant (Type II ANOVA, $\left.F_{(6,356)}=10.266, p<0.001\right)$, but the genotype of the deceased fish was not (Type II ANOVA, $\left.F_{(2,356)}=1.246, p=0.290\right)$. Offspring of $\mathrm{W} \times \mathrm{W}$ parents and $\mathrm{W} \times \mathrm{T} 400$ (female $\times$ male) parents lived significantly longer than offspring of the following crosses: $\mathrm{T} 400 \times \mathrm{T} 400, \mathrm{~T} 400 \times \mathrm{W}$, and T67 $\times \mathrm{W}$ (Tukey HSD, all adj. $p<0.024)$. Offspring of T67 $\times$ T67 parents also survived significantly longer than T400 $\times$ T400 offspring (Tukey HSD, adj. $p=0.029$ ).

When we compared means for longevity by genotype using multiple comparisons tests, $\mathrm{W}$ individuals lived significantly longer than T400 fish (Tukey HSD, W-T400, 
Relative fitness of transgenic medaka fish consistent with gene flow

Table 4. Summary statistics for longevity: mean \pm SD (in days; rounded to the nearest whole number) and $n$. NA indicates that offspring of a given genotype (rows) cannot result from a particular parental cross (columns).

\begin{tabular}{|c|c|c|c|c|c|c|c|}
\hline Maternal & $\mathrm{W}$ & $\mathrm{W}$ & $\mathrm{W}$ & T67 & T67 & T400 & T400 \\
\hline Paternal & W & T67 & T400 & W & T67 & W & T400 \\
\hline $\mathrm{W}$ & $\begin{array}{l}432 \pm 167 \\
(n=106)\end{array}$ & $\begin{array}{l}283 \pm 141 \\
(n=12)\end{array}$ & $\begin{array}{l}430 \pm 152 \\
(n=18)\end{array}$ & $\begin{array}{l}286 \pm 88 \\
(n=15)\end{array}$ & $\begin{array}{l}306 \pm 112 \\
(n=15)\end{array}$ & $\begin{array}{l}344 \pm 160 \\
(n=25)\end{array}$ & $\begin{array}{l}290 \pm 146 \\
(n=17)\end{array}$ \\
\hline T67 & NA & $\begin{array}{l}359 \pm 155 \\
(n=14)\end{array}$ & NA & $\begin{array}{l}329 \pm 99 \\
(n=14)\end{array}$ & $\begin{array}{l}382 \pm 172 \\
(n=29)\end{array}$ & NA & NA \\
\hline T400 & NA & NA & $\begin{array}{l}460 \pm 200 \\
(n=39)\end{array}$ & $\mathrm{NA}$ & NA & $\begin{array}{l}320 \pm 163 \\
(n=40)\end{array}$ & $\begin{array}{l}285 \pm 112 \\
(n=24)\end{array}$ \\
\hline
\end{tabular}

Table 5. Summary of fitness trait measurement experiments; different letters in superscript indicate significant $(p<0.05)$ differences between individuals of a given genotype or in a given trial, according to tests as described in Methods.

\begin{tabular}{|c|c|c|}
\hline Fitness trait & $\begin{array}{l}\text { Genotype rank, } \\
\text { with respect to fitness trait }\end{array}$ & $\begin{array}{l}\text { Genotype rank, with respect } \\
\text { to size of individuals used } \\
\text { to measure fitness trait }{ }^{1}\end{array}$ \\
\hline Fecundity & $\mathrm{T} 67^{\mathrm{a}}>\mathrm{W}^{\mathrm{a}}>\mathrm{T} 400^{\mathrm{a}}$ & $\mathrm{T} 400^{\mathrm{a}}>\mathrm{T} 67^{\mathrm{a}}>\mathrm{W}^{\mathrm{b}}$ \\
\hline Fertility & $\mathrm{T} 400^{\mathrm{a}}>\mathrm{T} 67^{\mathrm{a}, \mathrm{b}}>\mathrm{W}^{\mathrm{b}}$ & $\mathrm{T} 67^{\mathrm{a}}>\mathrm{T} 400^{\mathrm{a}}>\mathrm{W}^{\mathrm{b}}$ \\
\hline \multirow[t]{2}{*}{ Mating advantage $^{2}$} & $\mathrm{~W}^{\mathrm{a}}>\mathrm{T} 400^{\mathrm{b}}$ & $\mathrm{T} 400^{\mathrm{a}}>\mathrm{W}^{\mathrm{a}}$ \\
\hline & $\mathrm{W}^{\mathrm{c}}>\mathrm{T} 67^{\mathrm{d}}$ & $\mathrm{T} 67^{\mathrm{b}}>\mathrm{W}^{\mathrm{b}}$ \\
\hline Age at sexual maturity & $\mathrm{T} 67^{\mathrm{a}}<\mathrm{W}^{\mathrm{a}}<\mathrm{T} 400^{\mathrm{b}}$ & $\mathrm{T} 67^{\mathrm{a}}>\mathrm{W}^{\mathrm{a} 3}$ \\
\hline Juvenile viability & $\mathrm{W}^{\mathrm{a}}>\mathrm{T} 67^{\mathrm{a} 4}$ & NA \\
\hline Longevity & $\begin{array}{l}\mathrm{W}^{\mathrm{a}}>\mathrm{T} 67^{\mathrm{a}, \mathrm{b}}>\mathrm{T} 400^{\mathrm{b}} \\
\text { maternal genotype also significant: } \\
\mathrm{W}^{\mathrm{a}}>\mathrm{T} 67^{\mathrm{b}}>\mathrm{T} 400^{\mathrm{b}}\end{array}$ & NA \\
\hline
\end{tabular}

\footnotetext{
${ }^{1}$ Fish were weighed before inclusion in fitness trait experiments for fecundity, fertility, and mating advantage; fish were weighed when they reached sexual maturity for the age at sexual maturity measurement.

${ }^{2}$ Mating advantage relative genotype ranks are based on significance of intercept-only models, excluding trio matings, as described in Methods.

${ }^{3}$ Weight comparisons only available for T67 and W fish tested concurrently with T67.

${ }^{4}$ Data from trial 3 only.
}

adj. $p=0.032$ ), but not significantly longer than $\mathrm{T} 67$ fish (Tukey HSD, W-T67, adj. $p=0.913$ ).

\section{DISCUSSION}

The results of our invasion experiments and fitness trait measurements could be considered mutually supportive. In our invasion experiments, transgenic fish usually decreased in frequency, and most replicates resulted in a loss of all transgenic fish. No single genotype emerged as a clear "winner" on the basis of individual fitness trait measurements (Tab. 5). T400 males had a significantly higher fertility rate, and were significantly heavier than, $\mathrm{W}$ males. Wild-type males were more likely than T67 males to secure matings with $\mathrm{W}$ females. T67 and W females matured significantly sooner than T400 females, and $\mathrm{W}$ fish lived significantly longer than T400 fish. There were no significant differences between transgenic and wild-type fish in fecundity or juvenile viability, even though both T400 and T67 females in the fecundity measurement were significantly larger than $\mathrm{W}$ females.
In fact, male fertility was the only measurement in which the same genotype enjoyed a significant fitness and size advantage. Our fitness experiments therefore indicate that it may be insufficient to predict fitness advantages simply based on larger expected size.

\section{Characterization of transgenic lines}

We observed wild-type fish that were larger than some transgenic fish at about four months of age (Fig. 1), but the adult transgenic fish randomly selected for our fitness experiments were either larger or about the same size as the wild-type adults they were tested with (Tab. 5). Previous researchers have found that the T67 and T400 lines of medaka are larger than non-transgenic siblings from four to ten weeks of age (Jiménez, 2000) and at six weeks of age (Kruer et al., 2002), and research using a different strain of growth-enhanced transgenic medaka found they had the greatest size advantage before eight weeks of age (Muir and Howard, 2001). 


\section{Invasion experiments}

Our transgenic fish frequency results were not wholly unidirectional across replicates and experiments; therefore, they likely reflect the combined effects of random processes and varying selection pressures, as would occur if transgenic fish escaped into a wild population. Possible mechanisms for the different frequencies of transgenic fish at the end of the invasion experiments include: genetic drift, or random changes in frequency of the transgene, ultimately leading to its fixation or loss; a disease agent affecting demography; or differing selection pressures due to uncontrolled environmental variation among the mesocosms.

Genetic drift would be equally likely to result in an increased or decreased frequency of transgenic fish. The longer duration of invasion experiment II means that we were more likely to observe fixation or loss of the transgene; however, the fact that we observed a significant tendency towards loss in experiment II would indicate that this was not simply random drift, and one might conclude that the transgene confers a fitness disadvantage in the environment of the mesocosms.

To further test our gene flow results in the context of population genetics, we used the following equation to predict the number of generations to extinction of a selectively neutral mutant allele:

$$
[-4 \mathrm{~N} /(1-\mathrm{p})] \times[(\mathrm{p} \times \ln (\mathrm{p}))],
$$

where $\mathrm{N}$ is the effective population size and $\mathrm{p}$ is the initial frequency of the mutant allele (Hartl and Clark, 1997: p. 282; after Kimura and Ohta, 1969). We conservatively estimated the effective population size using census data from our mesocosms: half the initial population size $\left(\mathrm{N}_{\mathrm{I}}=373\right.$ and $\left.\mathrm{N}_{\mathrm{II}}=517\right)$ and half of the smallest final population size observed in any experimental mesocosm $\left(\mathrm{N}_{\mathrm{I}}=62\right.$ and $\left.\mathrm{N}_{\mathrm{II}}=48\right)$. We estimated allele frequency as the starting frequencies of transgenic fish from both experiments $\left(\mathrm{p}_{\mathrm{I}}=0.054\right.$ and $\left.\mathrm{p}_{\mathrm{II}}=0.077\right)$. Using half of the initial population as our estimates of effective population size, the formula predicted loss of the transgene in 124 and 221 generations in invasion experiments I and II, respectively. Even the estimates using half of the lowest final population size as the effective population size predicted that a selectively neutral transgene would avoid loss until after an average of 21 generations for both invasion experiments. Because in invasion experiment II, transgenic fish disappeared from five out of six replicates in less than half that time (19 months or 9.5 generations, assuming a two-month generation time for medaka), this simulation provides further evidence that the transgene was not selectively neutral. Subsequent screening of transgenic broodstocks showed that not all transgenic fish were homozygous for the transgene, so we also estimated mean time to loss assuming that half the transgenic fish were hemizygous (i.e. $0.75\left(\mathrm{p}_{\mathrm{I}}\right)$ and $\left.0.75\left(\mathrm{p}_{\mathrm{II}}\right)\right)$. In that case, mean predicted time for loss of the transgene was 100 and 181 generations for experiment I and II, respectively, when we used half the initial population sizes as N. When we used half of the lowest final population size as $\mathrm{N}$, the equation predicted the allele would be lost after about 17 generations in both experiments. Compared to even this conservative estimate, we observed loss of the transgene in a shorter period in our invasion experiments.

We did observe the effect of an unpredictable agent of demographic change due to the M. haemophilum infection. Our invasion experiments were initiated before the first published occurrence of $M$. haemophilum in fish (Kent et al., 2004), in which an outbreak among zebrafish (Danio rerio) was first described. We observed medaka in the invasion experiments with symptoms similar to those subsequently reported in infected zebrafish, such as inflammation and emaciation (Whipps et al., 2007). All mesocosms in both experiments, including wild-type-only control populations, experienced population declines at a similar rate, and of comparable magnitude. The disease could have affected the frequency of transgenic fish in the experimental mesocosms through differential mortality, although the similar rate of population decline in the wild-type-only control populations contraindicates this possibility. We did not investigate the cause of death of individual wild-type and transgenic fish.

We monitored and kept constant most environmental factors, including temperature, photoperiod, food availability, and water chemistry, across mesocosms and in both invasion experiments. Differences in water clarity between mesocosms in experiment I might have influenced visually-affected behaviors such as mating, aggregation, and food foraging (e.g., Guthrie and Muntz, 1993) leading to different selection pressures between mesocosms and therefore more variation in results in experiment I than in experiment II. The suppression of suspended algae and introduction of macrophytic algae in invasion experiment II may have also contributed to environmental differences between the two invasion experiments.

Our interpretation of the invasion experiment results is limited by the number of replicates and limited quantitative data on the fate of the founding population. Because we wanted to simulate large populations of wild-type fish, we could only accommodate three mesocosms for each treatment. Additional replicates may have strengthened the conclusions we could make about the fate of transgenic fish in these populations. Also, because we did not mark fish that were introduced to the mesocosms at the beginning of the experiment, we could not be certain about what proportion of adults at 
the end of the invasion experiment were founders and which were fully-grown fish born during the course of the experiment.

\section{Fitness measurements}

\section{Fecundity}

In spite of the fact that transgenic females weighed more than wild-type females in our experiments, we did not detect differences in fecundity between genotypes. Fecundity in fish is generally positively associated with size (e.g., Jobling, 1995) and previous studies using medaka have found a positive weight-fecundity relationship (Muir and Howard, 2001). We observed a negative weight-fecundity relationship in these experiments. One possible explanation is that four females (one T400, one T67, and two W) out of 72 females in our experiments did not produce any eggs during the ten-day trial. These females weighed more $(0.7103 \pm 0.1575 \mathrm{~g}, n=4)$ than females that produced some eggs during the trial $(0.4802 \pm 0.1324 \mathrm{~g}, n=68)$; however, this difference was not significant $\left(t\right.$-test, $\left.t_{(\mathrm{df}=3.255)}=2.863, p=0.0585\right)$.

\section{Fertility}

T400 males had significantly greater fertility than $\mathrm{W}$ males, but not significantly greater than T67 males, in our bootstrap simulation. In our experiments, we observed lower fertility among T67 males than W males; however, the variance in fertility rate for T67 males was the highest, possibly accounting for the lack of significant differences between this genotype and the others in the bootstrap analysis. The standard deviation among T400 males is much smaller, partly because we removed data from two T400 males that fertilized no eggs and from two T400 males that were paired with a female that did not bear eggs during the trial. Therefore, we only used data from six T400 males, which all had very high fertilization rates.

Our observations of high fertility rates are consistent with previous studies of male fertilization success in medaka (Muir and Howard, 2001); further suggesting that the three lowest-fertility males were genuinely unusual observations. Muir and Howard (2001) did not find a difference in the fertilization success of transgenic and wild-type males.

\section{Mating advantage}

In these experiments, both lines of transgenic males were heavier, on average, than the $\mathrm{W}$ males; however, $\mathrm{W}$ males obtained a larger proportion of matings with females.
This contrasts with (1) the general assumption that larger males will have a competitive advantage in seeking matings (i.e., Andersson, 1994), and (2) previous medaka research that found that larger males (Howard et al., 1998) and larger, transgenic males (Howard et al., 2004) have a mating advantage over smaller and wild-type males. However, in both of Howard et al.'s (1998 and 2004) medaka mating advantage studies, the larger males of each genotype were competing against males with the same genetic background. In our study, the transgenic and wild-type males were derived from different populations of fish descended from medaka from Japan. The differences in genetic background between the source populations of transgenic and wild-type fish could have led to the differences in mating advantage results (e.g., Kapuscinski et al., 2007), because different strains of unmodified fish have been found to express different values for some important components of fitness (e.g., McGinnity et al., 2003).

Given that we observed a high incidence of trio matings, even a small difference in fertilization success between the first and second, or "joiner," male, could result in a substantial difference in paternity among offspring of such matings. Iwamatsu et al. (1991) suggest that most micropyles on the medaka egg are occupied by sperm after six seconds of exposure to high sperm concentrations, so it is possible that a late-joining male would fertilize a lower proportion of eggs. Howard et al. (2004) found that "joiner" male medaka fertilized about $23 \%$ of eggs in trio matings. We did not test the genotype of eggs or offspring to determine paternity. However, we did model "worst-case" scenarios in which the males of one genotype fertilized all the eggs during trio matings. Our results suggest that even if transgenic males were fertilizing all the eggs in trio matings, they still would not have a significant overall mating advantage over wild-type males.

\section{Age at sexual maturity}

T67 and W females matured before T400 fish. Even the T400 fish in our experiments produced eggs at an earlier age than previously reported for wild-type medaka (i.e., $64.3 \pm 1.27$ days reported by Jiménez, 2000). This could be due to our choice to test only the first five females in each aquarium to reach sexual maturity, as we were most interested in the earliest-maturing fish in a population.

\section{Juvenile viability}

Our juvenile viability data are incomplete because dead fry, particularly those just a few days old, were very difficult to detect in our experiments. This could be due to scavenging by tankmates. Fry not found immediately 
had degraded tissue and we were unable to recover genotypic information from these individuals. In trial 1, offspring of two T400 parents were significantly less likely to survive to sexual maturity than offspring of one or no transgenic parent(s). Our findings are consistent with a previous study of medaka, which found offspring of two transgenic parents to have relatively lower viability (Muir and Howard, 2001).

During trial 3, most of the fish died in groups before reaching sexual maturity, making observation and collection of dead tissue - and subsequent genotyping more feasible. Simultaneous die-offs occurred across all parental crosses and genotypes. This age range (1530 days old) may be a period of vulnerability and mortality due to increased competition from tank mates or another factor. Because aquaria in which we measured juvenile viability did not have refugia like the mesocosms had, it is possible that faster-growing tankmates were able to cannibalize smaller fry during this time period. However, in the mesocosms, fry could have been exposed to much larger adults, which would be more likely to cannibalize fry due to their gape size.

\section{Longevity}

Overall longevity in our experiments was high, with a mean lifespan of over a year. The natural lifespan of medaka is thought to be approximately one year (unpublished data, cited in Shima and Mitani, 2004). We observed a maternal effect on longevity; fish with W mothers had a significantly longer lifespan than transgenic medaka, and $\mathrm{W}$ fish survived significantly longer than T400 fish. Muir and Howard's (2001) model to predict gene flow from transgenic fish using fitness trait estimates was least sensitive to longevity, therefore differences in this fitness trait may be less likely to impact population processes like gene flow.

\section{Summary}

The consistency of our results between the fitness trait data and invasion experiments imply that ecological risk assessments may be able to utilize fitness trait data to predict the fate of transgenic fish invading a wild-type population, provided that the fitness trait data are collected under environmental conditions approximating those of the ecosystems at issue. Indeed, the aquaria we used to measure fitness traits had environmental conditions mostly similar (exceptions are discussed below) to those in the invasion experiment mesocosms (i.e., our ecosystem at issue). In invasion experiment I, the frequency of transgenic fish increased in two T400-invaded populations, consistent with our findings of a T400 fertility advantage over wild-type fish. The results of invasion experiment II, at the end of which no T400 and only one T67 fish remained, are consistent with our results for age at sexual maturity, longevity, and mating advantage, in which wildtype fish had an advantage over one of the transgenic lines. In most of the invasion experiment populations, transgenic fish did not successfully invade the wild-type population.

\section{Limitations and future research}

Although some generalizations can be made about our invasion experiment and fitness measurement results, and the relationship between them, our ability to conclude that the fate of transgenic fish in the invasion experiments was a causal result of fitness differences is limited by several factors. First, while a number of physical properties of the environment were the same between the invasion and fitness experiments (temperature, water source, photoperiod), there were also differences between the invasion and fitness experiments: the invasion experiments took place in a larger volume of water accommodating a larger population size, with corresponding effects on density; fitness measurements were in glass aquaria and invasion experiments in opaque fiberglass tanks, with potential effects on fish behavior; disease effects occurred only in the invasion experiments; and there was more cover in the invasion experiments, including artificial refugia and micro- or macro-algae. Future experiments of this type should endeavor to incorporate key elements of the environment into which a transgenic animal would be likely to escape. Finally, because we compared wild-type fish and transgenic fish derived from different genetic backgrounds, we cannot distinguish between results that were effects of the transgene construct itself and results that may have derived from genetic background effects (i.e., Kapuscinski et al., 2007). Indeed, the genetic background into which a transgene is inserted can affect the phenotype of the resulting transgenic strain; a growth hormone transgene had far more dramatic impacts when inserted into a wild-type strain of rainbow trout (Oncorhynchus mykiss) compared to transgenic fish derived from a selectively bred line (Devlin et al., 2001). To distinguish between these effects, investigators can compare an additional strain with the same genetic background as the transgenic fish but without the transgene (as in Bessey et al., 2004).

Our fitness and invasion experiment results will not necessarily apply to other growth-enhanced transgenic fish; each transgenic fish strain should be evaluated on a case-by-case basis (Kapuscinski et al., 2007). Studies of transgene flow should span many generations and include a number of replicates in order to distinguish between 
potentially large effects of stochastic processes and natural selection (Hill, 1971). This may be impractical for species with long generation times or complex life histories (e.g., migratory salmon), but is no less important.

We recommend that future transgenic gene flow experiments in animals reflect the type and degree of variation in environmental factors affecting the animal's ability to survive and reproduce in nature due to the potential fitness effects of genotype-by-environment interactions. Risk assessment scientists need to better understand how these interactions might be incorporated into risk assessments of transgenic fish. The impact of environmental variation on transgenic and wild-type fish has been considered one of the greatest challenges to our ability to predict the ecological risk of transgenic fish (Devlin et al., 2006; National Research Council, 2008).

Simulation modeling could help assess the effects of stochastic processes and selection on transgene fate, as long as parameters reflect empirical knowledge of major selection forces in the species' natural environment. Gene flow between crop and wild sunflowers can be predicted with some accuracy when fitness measurements are taken from the field (Cummings et al., 2002). However, releasing transgenic fish into a wild environment for study is too risky; some investigators have used fish injected with growth hormone to study the effects of fastgrowing fish in a more natural environment (Johnsson et al., 1999), though simulating the phenotypic effects of a transgene at various life stages has some challenges (Devlin et al., 2007) and may be even less straightforward with other transgenic traits, for example temperature tolerance or disease resistance. Using simulated phenotypic effects would be insufficient for multiple-generation studies like the one presented here. It is almost certain that environments into which transgenic fish might escape will be more complex than those we are able to recreate in confined laboratories. Therefore, it remains to be seen whether models of transgene flow based on estimates of fitness measurements taken under relatively sterile conditions (i.e., Aikio et al., 2008; Muir and Howard, 2001), can accurately predict the frequency of transgenic fish in a population many generations after an escape event.

\section{MATERIALS AND METHODS}

\section{Confirmation of transgene inheritance and expression}

Japanese medaka in wild-type and transgenic founder populations were housed separately according to genotype. When transgenic medaka reproduced, we used polymerase chain reaction (PCR) to determine which offspring had inherited the transgene. To obtain tissue for genetic analysis, we sampled a small $(<1 \mathrm{~mm})$ strip of tissue from the distal end of the caudal fin, using sterile procedure. We placed this tissue in labeled tubes containing $200 \mu \mathrm{L}$ of a $10 \%$ Chelex solution (Sigma) and processed it according to Miller and Kapuscinski's (1996) DNA extraction protocol. We used sGH primers (SGHFOR: 5' -TCG CGC AGT ATA ATG AAA T-3' and SGHREV: 5'-TAA GAG CGC TGG GTC GTT A-3'; Integrated DNA Technologies, Coralville, IA) to identify transgene-positive fish, and we used primers for the betaactin gene (MBAFOR: 5'-GTA GCG TAT GGG TTG GGT-3' and MBAREV: 5'-AGC AGA ATG CCA CCT CAG A-3'; Integrated DNA Technologies, Coralville, IA) as a control. Each reaction mixture contained $5 \mu \mathrm{L}$ Chelex template DNA solution, $10 \mu \mathrm{L}$ PCR Master Mix (Promega), 8 pmol of sGH primers and 2 pmol of betaactin primers. We carried out PCR with $20 \mu \mathrm{L}$ reaction mixtures, and ran PCR in a Hybaid Omn-E thermal cycler at the following temperature profile for 35 cycles: denaturing at $94{ }^{\circ} \mathrm{C}$ for $30 \mathrm{~s}$, annealing at $50{ }^{\circ} \mathrm{C}$ for $30 \mathrm{~s}$, and elongating at $72{ }^{\circ} \mathrm{C}$ for $30 \mathrm{~s}$, followed by a final elongation period of $10 \mathrm{~min}$. After electrophoresis on a $1 \%$ agarose gel stained with ethidium bromide, we visualized PCR products under ultraviolet light. Individuals were compared to lanes containing PCR product from previously confirmed wild-type and transgenic control individuals. Transgene-negative fish were identified by a single band (beta-actin control), and transgene-positive fish were identified with two bands (beta-actin and sGH transgene).

To confirm expression of the transgene in T400 and T67 medaka, we submitted seven transgenic and one wild-type fish for reverse-transcriptase PCR (RTPCR) at the BioMedical Genomics Center (University of Minnesota, Saint Paul, MN, USA). Total RNA was extracted from fish, homogenized in Trizol reagent (Invitrogen, CA, USA) and its quality was checked on the Agilent Bioanalyzer 2100 (Agilent Technologies, CA, USA). First strand cDNA synthesis was conducted from $2 \mu \mathrm{g}$ of total RNA from each sample, using oligo $\mathrm{dT}_{(12-18)}$ primers and SuperScript II reverse transcriptase (Invitrogen). Gene expression analysis was performed using SYBR Green chemistry on an Applied Biosystems 7900 Real-Time PCR system with reagents purchased from Applied Biosystems. All PCR reactions were performed in triplicate and the experiments were replicated a minimum of three times. The amplification product was checked on a $2 \%$ agarose gel.

\section{Invasion experiments}

\section{Model population}

We monitored the weight over time of 15 fish of each (W, T67, and T400) genotype. This experiment was 
concurrent with invasion experiment II and some fitness measurements, so the fish randomly selected for growth monitoring were not included in any other experiments. Fish were held by genotype in three ten-gallon aquaria with similar environmental conditions, and were fed to satiation like fish in the fitness and invasion experiments. We began with 7-week-old fish, and weighed each fish weekly for 10 weeks. We were able to identify the genotype of 7-week-old fish using PCR, but they were still too small to positively identify as male or female, so we did not differentiate between sexes. One wild-type fish died at age 12 weeks. We analyzed these data to compare average weight of each genotype at different points in time, using Tukey HSD multiple comparisons tests.

\section{Experimental design}

To investigate the pattern of gene flow from transgenic to wild relatives, we released transgenic fish into populations of wild-type relatives in mesocosms with structural complexity in their environments. The mesocosms were nine $1500-\mathrm{L}$, semi-square fiberglass tanks. To promote natural reproduction, hanging spawning grasses were provided on which females could deposit eggs. Photoperiod (16 h light:8 h dark) and temperature $\left(26^{\circ} \mathrm{C}\right)$ were controlled and optimized for reproductive activity (Shima and Mitani, 2004). Refugia were provided so that juvenile fish could voluntarily escape from cannibalistic adult medaka.

Transgenic invasion experiments were repeated twice. We conducted experiment I for the equivalent of three generations (six months). After the completion of experiment I, we conducted experiment II for nearly ten generations (nineteen months). Large populations of wild-type medaka were established in each of nine mesocosms. Three control mesocosms contained only these wild-type fish. To simulate a small escape of farmed fish (a frequent event; National Research Council, 2004), we released T67 transgenic medaka into three of the nine mesocosms and T400 transgenic medaka into three others (Tab. 1). Adult fish were fed to satiation once daily with flake food (O.S.I. Marine Lab) and 24-h-old brine shrimp nauplii (Artemia spp.) hatched from cysts (Aquatic Eco-Systems) in our lab. Fry in refugia were fed Artificial Plankton Rotifer (APR; O.S.I. Marine Lab).

To determine final population size and frequency of transgenic fish, we counted and genotyped all fish in each population when both invasion experiments were terminated. In addition, we randomly sampled fish $(n=30)$ from each experimental population to confirm that transgenic fish remained in at least one of the populations during invasion experiment II.

In experiment I, water clarity in the mesocosms gradually decreased as suspended algal density increased, making it difficult to identify and remove mortalities and monitor fish health. In the hopes of controlling algae in experiment II, ultraviolet sterilizers were installed on all mesocosms and succeeded in maintaining water clarity. However, fish eventually appeared stressed by the lack of cover, so we introduced two different species of floating macro-algae in equal amounts by weight across all mesocosms: duckweed (Lemna minor) and water sprite (Cereus spp.). Eight months after the initiation of experiment II, $130 \mathrm{~g}$ (wet weight) of duckweed was introduced to each mesocosm. In the following month, $30 \mathrm{~g}$ of water sprite was added to each mesocosm.

\section{Data analysis}

We used binomial sign tests to compare the final transgene frequencies in both invasion experiments. An increased final transgene frequency was considered a "success" while a transgene frequency less than the initial transgene frequency, including a result of zero transgenic fish, was considered a "failure". We performed these tests with the null hypothesis that, if the transgene is selectively neutral, the transgene frequency is equally likely to increase or decrease. We also compared ending population sizes in each mesocosm across treatments using an Analysis of Variance (ANOVA) model and Tukey Honestly Significant Difference (HSD) multiple comparisons tests. To analyze our data, we used the open-source statistical software R (R Development Core Team, 2008), and where $p$-values were obtained, we set $\alpha=0.05$ as the threshold for significance.

\section{Fitness trait measurements}

Concurrent with the invasion experiments, we measured selected life-history components of wild-type (W) medaka and the two transgenic lines (T400 and T67): fecundity, fertility, mating advantage, age at sexual maturity, juvenile viability, and longevity.

We measured the following three fitness traits on adult fish of approximately the same age across genotypes: fecundity, male fertility, and mating advantage. Using a random number generator, we randomly selected fish temporarily held in numbered Petri dishes for these experiments from the same source population as the fish introduced into the invasion experiments, but we did not use the same individual fish. Fecundity and fertility data were collected in four consecutive trials: in trials 1 and 2 we measured traits of T400 fish and wild-type fish together, and four months later, in trials 3 and 4 we measured T67 fish with a different set of wild-type fish. Mating advantage experiments occurred separately, with different adult 
fish. We measured fecundity, fertility, and mating advantage in 5-gallon static glass aquaria with photoperiod controlled at 16:8 (light:dark) and temperature of approximately $26^{\circ} \mathrm{C}$. Adult fish were fed to satiation with flake food and live brine shrimp nauplii.

We randomly selected two consecutive days of each trial of the fecundity and fertility experiments, and retained all fertile eggs from those two days. We incubated those eggs, separated by the cross (maternal $\times$ paternal genotype) that produced them and by the trial (1-4) during which they were produced. When the eggs hatched after 8-10 days, we randomly selected 50 fry from each cross and placed them in 30-gallon glass aquaria. We used these fish to measure the remaining three fitness trait measurements: age at sexual maturity, juvenile viability, and longevity. We fed fry only APR until about 10 days of age, when we added brine shrimp nauplii to their diet. We began to replace APR with crushed flake food when fry reached about 20 days of age.

We performed all analyses of fitness trait measurements using R (R Development Core Team, 2008), and created a number of figures using the R package "lattice" (Sarkar, 2008). As for the invasion experiment data analysis, we considered $p<0.05$ to be significant.

\section{Fecundity and fertility: Experimental design}

We measured fecundity as the total number of eggs produced by a female fish, and fertility as the proportion of intact eggs containing embryos that were successfully developing $24 \mathrm{~h}$ after their collection. Several days before beginning trial 1 , we randomly selected 10 females and 10 males of each genotype (W and T400), weighed them, and arranged the 20 pairs of fish in four types of crosses (with the letter representing the female genotype first, $\mathrm{W}=$ wild-type and $\mathrm{T}=$ transgenic): $\mathrm{WW}, \mathrm{WT}, \mathrm{TW}$, and TT. Between trials 1 and 2, we weighed the individuals used in trial 1 and rearranged them for use in trial 2, except for replacing a few fish that did not survive the experiment with individuals of the same sex and genotype. We used the same procedure to select fish for use in trials 3 and 4, in which we selected a different set of wild-type fish and transgenic fish were of the T67 line.

We collected eggs from females every morning for ten consecutive days, and placed eggs from each pair of fish in separate, labeled mesh-bottom cups in a flowing-water bath with a methylene blue solution to inhibit fungal growth on eggs. Twenty-four hours later, we counted the total number of eggs in each cup, the number of embryos that were successfully developing, and noted whether any eggs were broken due to handling.

\section{Fecundity: Data analysis}

We summed each female's total egg production during each ten-day trial. We excluded eight cases in which the female was replaced in the middle of a trial. Four females failed to produce any eggs during the entire ten-day test period but were included in our analysis because they survived the entire experiment. We included eggs that were broken or infertile in the count of total egg production.

We analyzed fecundity data with a Type II ANOVA in which ten-day egg production was dependent on female genotype. In analyses, we included trial number and male genotype as blocking factors and the starting weight of the female as a covariate. We also compared ten-day egg production by females of different genotypes with a Tukey HSD multiple comparisons test.

\section{Fertility: Data analysis}

We calculated a ten-day overall fertility rate for each trial as overall fertility rate $=(n$ fertile eggs $) /(n$ intact eggs $)$. To remove the effect of female genotype on male fertility, we only used eggs from wild-type females (Muir and Howard, 2001). We excluded data from two $\mathrm{W}$ males that died during trial 1, and data from two T400 males that were paired with a female that did not produce any eggs during the course of the trial.

We also excluded data from three males that otherwise met criteria for inclusion, but that had unusually low fertility rates. Two T400 transgenic males fertilized zero eggs and one W male had an overall fertility rate of only 0.077 . Two of these males were tested with the same female, and the third male was tested with a female that died in the middle of the trial. Because total egg production during all three males' trials was very low (fewer than 26 intact eggs during a trial, only $15 \%$ of mean egg production), these individuals had fewer opportunities to fertilize eggs.

We created a binomial generalized linear model for the overall fertility rate, including trial as a blocking variable and male weight at the beginning of a trial as a covariate, and dependent on male genotype. To correct for overdispersion in our data, we calculated dispersion parameters for each model. Because of relatively small sample sizes, we ran bootstrap simulations ( $n=100$ simulations) and generated $95 \%$ confidence intervals (CI), with a Bonferroni correction for multiple comparisons, for the differences in fertility between male genotypes.

\section{Mating advantage: Experimental methods}

We tested the relative mating advantage of transgenic and wild-type male medaka by placing one transgenic male 
and one wild-type male in an aquarium with one wildtype female and scoring males according to which male successfully obtained a mating with the female. We conducted tests in five aquaria with removable dividers that separated the males from the female between mating opportunities. The only structure in the aquaria was a small sponge filter that provided biofiltration and aeration to the aquaria. We designed the mating advantage experiments so that each combination of one female and two male fish was unique. Each wild-type female resided in the same aquarium during the entire experiment. Each of the five wild-type and five transgenic males were moved among aquaria according to a Latin square design so that any given wild-type male only competed once with each transgenic male, and all males encountered each female exactly once. We randomly selected fish for this experiment, and, before the experiment, we weighed, photographed, and noted any distinguishing features of the males so we could identify individuals during the experiment. We tested both transgenic lines for five test periods, each four to six days long, with several days in between each test period to move fish and to allow them to acclimate to their new aquaria.

During each day of a mating advantage experiment, we removed the tank dividers just before the lights turned on, and then watched the fish in all five aquaria as males competed to mate with the female. We gave males a score of 0 (failure to mate with the female) or 1 (successful mating with the female) for each day of the test period. Male medaka perform an elaborate courtship dance, often swimming in a spiral under the female before attempting to clasp her using their anal and dorsal fins. If the female does not reject the male's advances, a "successful mating" resulted after the fish quiver together, which results in the female releasing a clutch of eggs (Uematsu, 1990). It is not uncommon to observe "trio" matings in medaka, in which both males mate simultaneously with the female (Howard et al., 2004). We noted such occurrences separately. If neither male mated with the female within approximately two hours of the beginning of observations, both males received a 0 score for that day.

We tested each transgenic line with separate sets of wild-type fish. We tested T400 males first. We randomly selected five $\mathrm{W}$ females, five $\mathrm{W}$ males, and five T400 transgenic males and assigned each to an aquarium. Of the five test periods with T400 males, three lasted five days and two were extended to six days of observation due to low mating success at the beginning of the test periods. We replaced a number of $\mathrm{W}$ and T400 males that sickened or died between test periods, resulting in a total of 12 different T400 males and 13 different $\mathrm{W}$ males during the T400 experiments. We weighed fish before they were included in the experiment, but did not weigh individuals between each test period.
We tested the T67 transgenic line several months later, in five test periods that lasted exactly four days each. We weighed each fish before the experiment and between each test period. All other methods were the same as those described above for the T400 transgenic line. We replaced one $\mathrm{W}$ female, two $\mathrm{W}$ males, and two T67 males that died during the experiment, but no fish died during a test period.

\section{Mating advantage: Data analysis}

In our analysis, we excluded data from the following tanks with no successful matings: in the T400 experiments, one tank in the second test period and one tank in the fifth test period, and one tank in the fifth test period of the T67 experiments. We also excluded data from three T400 test periods during which females died and were replaced.

We used binomial generalized linear models in which wild-type matings were "successes," transgenic matings were "failures," and trio matings were excluded, and which were fitted with only an intercept term to test the odds of wild-type matings versus transgenic matings. To test the mating advantage of each genotype under the extreme scenario that the male of one genotype fertilized all eggs in trio matings, we created a second set of binomial models in which trio matings were combined as "successes" with each male genotype in turn. We designed the rest of our analysis to predict the likelihood of one of three different types of matings during a test period: matings obtained by transgenic males alone, wild-type males alone, and trio matings.

\section{Age at sexual maturity: Experimental methods and analysis}

We measured age at sexual maturity by the age in days of the first five female offspring from each cross to produce viable eggs. Every morning, we visually inspected each aquarium for females with eggs. When a female with eggs was discovered, we removed her from the aquarium, weighed her, and collected a small sample of caudal fin tissue for PCR identification of the female's genotype. We held the first clutch of eggs from each aquarium in a flow-through egg incubator, and checked for successful development after $24 \mathrm{~h}$ to ensure that at least one male in the aquarium was also sexually mature. We removed the data for one fish that we were unable to successfully PCR.

We used a Type II ANOVA model to predict age at sexual maturity with the genotype of the sexually mature fish, and trial as a blocking factor. Fish with one transgenic parent that did not inherit the transgene were counted along with "W" fish. 


\section{Juvenile viability: Experimental methods and analysis}

We measured juvenile viability by counting fish that died before reaching sexual maturity. However, we were unable to retrieve tissue from mortalities in the aquaria before sexual maturity in trials 1 and 2, because they decayed or were cannibalized before they were observed. Therefore, we counted the remaining fish in trial 1 and 2 aquaria after those fish were sexually mature (at 74 and 64 days of age, respectively). For offspring from trials 3 and 4 , we closely monitored tanks for mortalities until fish reached sexual maturity. We only collected dead fry for PCR analysis in trial 3 tanks; we did not detect any mortalities before sexual maturity in trial 4 .

We compared juvenile viability data for trial 1 on the basis of parental cross using a chi-squared contingency table. We excluded data for trial 2 from analysis because the number of fish in each aquarium after sexual maturity was greater than the number expected (i.e., errors may have been made when initially stocking fry). We analyzed juvenile viability data for trial 3 with a chi-squared table. In our analysis for trial 3, we removed the data for two fish that we were unable to successfully PCR.

\section{Longevity: Experimental methods and analysis}

We measured longevity as the number of days fish survived. We used the same aquaria of fish that we used to measure age at sexual maturity and juvenile viability. We monitored these aquaria daily for mortalities, and we used PCR to identify whether deceased fish were transgenic. Fish with one transgenic parent that did not inherit the transgene were counted along with "W" fish.

We used a square-root transformation of longevity to improve normality in the data. We used a Type II ANOVA to determine the effect on longevity of the deceased fish's genotype and the parental cross, with trial included as a blocking factor. We removed data from 163 fish (of a total $n=531$ ) whose genotype we were unable to determine using post-mortem PCR. Tukey HSD multiple comparisons tests were used to compare the effects of different factors on longevity.

\section{ACKNOWLEDGEMENTS AND AUTHOR CONTRIBUTIONS}

K.M.P. and A.R.K. contributed equally to this work. A.R.K., K.M.P. and M.S.M. refined the design of invasion experiment I and designed invasion experiment II. M.S.M. designed and built the mesocosms. K.M.P. and M.S.M. ran the experiments. K.M.P. analyzed the data. A.M.C. and L.M.M. ran the PCR analyses of sampled fish. L.M.M. assisted with population genetics analyses. A.R.K. supervised the transgenic fish release experiments and extensively discussed the results and wrote the paper with K.M.P. All authors commented on the manuscript. We thank J. Maher, O. Göktepe, K. Maccaroni, M. Michaelis, A. Tri, and T. Zhou for technical assistance; W. Muir for contributions to the experimental design, comments on drafts of this paper, and provision of fish from the T67 and T400 lines; R. Devlin for provision of the construct used to produce the transgenic fish; A. Rendahl of the University of Minnesota Statistical Consulting Service for assistance with analyses; and S. Singh for gene expression analysis. J. Curtsinger, G. Dana, M. Hove, N. Jordan, B. Martinez, K. Oberhauser, L. Sharpe, M. Williams, and three anonymous reviewers provided useful comments on this manuscript. B. Harris and S. RobbeAusterman helped to diagnose the Mycobacterium infection. A.R.K. received funding from: USDA Biotechnology Risk Assessment Grant (as co-principal investigator with W. Muir), Pew Fellowship in Marine Conservation, Minnesota Sea Grant College Program (NOAA office of Sea Grant, United States Department of Commerce, grant number NA16RG1046), and Sherman Fairchild Professorship (Dartmouth College). K.M.P. was funded by an NSF Graduate Research Fellowship and University of Minnesota Doctoral Dissertation Fellowship. This paper is journal reprint number JR 567 of the Minnesota Sea Grant Program.

Received March 15, 2010; accepted September 20, 2010.

\section{REFERENCES}

Aikio S, Valosaari KR, Kaitala V (2008) Mating preference in the invasion of growth enhanced fish. Oikos 117: 406-414

Andersson M (1994) Sexual Selection. Princeton University Press, Princeton

Aqua Bounty Technologies (2010) Interim results for the six months ended 30 June, 2010. http://www. aquabounty.com/documents/press/2010/2010\%2009.15\%20\%20Interim\%20Results.pdf (Accessed September 21, 2010)

Bessey C, Devlin RH, Liley NR, Biagi CA (2004) Reproductive performance of growth-enhanced transgenic coho salmon. Trans. Am. Fish. Soc. 133: 1205-1220

Chan W-K, Devlin RH (1993) Polymerase chain reaction amplification and functional characterization of sockeye salmon histone $\mathrm{H} 3$, metallothionein-B, and protamine promoters. Mol. Mar. Biol. Biotech. 2: 308-318

Cummings C, Alexander H, Snow A, Rieseberg L, Kim M, Culley T (2002) Fecundity selection in a sunflower crop-wild study: Can ecological data predict crop allele changes? Ecol. Appl. 12: 1661-1671 
Devlin RH (1993) Sequence of sockeye salmon type 1 and 2 growth hormone genes and the relationship of rainbow trout with Atlantic and Pacific salmon. Can. J. Fish. Aquat. Sci. 50: $1738-1748$

Devlin RH, Yesaki TY, Biagi CA, Donaldson EM, Swanson P, Chan W-K (1994) Extraordinary salmon growth. Nature 371: 209-210

Devlin RH, Biagi CA, Yesaki TY, Smailus DE, Byatt JC (2001) Growth of domesticated transgenic fish. Nature 409: $781-782$

Devlin RH, Sundström LF, Muir WM (2006) Interface of biotechnology and ecology for environmental risk assessments of transgenic fish. Trends Biotechnol. 24: 89-97

Devlin RH, Sundström LF, Johnsson JI, Fleming IA, Hayes KR, Ojwang WO, Bambaradeniya C, ZakariaIsmail M (2007) Assessing ecological effects of transgenic fish prior to entry into nature. In Kapuscinski AR, Hayes KR, Li S, Dana G, eds, Environmental Risk Assessment of Genetically Modified Organisms, Volume 3: Methodologies for Transgenic Fish, CAB International, Oxfordshire, UK, pp 151-187

Fleming IA, Hindar K, Mjolnerod IB, Jonsson B, Balstad T, Lamberg A (2000) Lifetime success and interactions of farm salmon invading a native population. P. Roy. Soc. B - Biol. Sci. 267: $1517-1523$

Food and Drug Administration (2010) Veterinary Medicine Advisory Committee; notice of meeting. August 26, Federal Register 75: 52605

Guthrie DM, Muntz WRA (1993) Role of vision in fish behaviour. In Pitcher TJ, ed, The behaviour of Teleost fishes, Chapman \& Hall, London, pp 89-121

Hartl DL, Clark AG (1997) Principles of Population Genetics. Sinauer, Sunderland, MA

Hedrick PW (2001) Invasion of transgenes from salmon or other genetically modified organisms into natural populations. Can. J. Fish. Aquat. Sci. 58: 841-844

Hill WG (1971) Design and efficiency of selection experiments for estimating genetic parameters. Biometrics 27: 293-311

Hindar K, Ryman N, Utter F (1991) Genetic effects of cultured fish on natural fish populations. Can. J. Fish. Aquat. Sci. 48: $945-957$

Howard RD, Martens RS, Innis SA, Drnevich JM, Hale J (1998) Mate choice and mate competition influence male body size in Japanese medaka. Anim. Behav. 55: 1151-1163

Howard RD, DeWoody JA, Muir WM (2004) Transgenic male mating advantage provides opportunity for Trojan gene effect in a fish. P. Natl. Acad. Sci. 101: 2934-2938

Iwamatsu T, Onitake K, Yoshimoto Y, Hiramoto Y (1991) Time sequence of early events in fertilization in the medaka egg. Dev. Growth Differ. 33: 479-490

Jiménez LV (2000) Estimation of fitness components in transgenic Japanese medaka to assess environmental risk in genetically modified organisms. Ph.D. thesis, Purdue University, West Lafayette, Indiana

Jobling M (1995) Environmental Biology of Fishes. Chapman \& Hall, London

Johnsson JI, Petersson E, Jönsson E, Björnsson BT, Järvi T (1996) Domestication and growth hormone alter antipredator behaviour and growth patterns in juvenile brown trout, Salmo trutta. Can. J. Fish. Aquat. Sci. 53: 1546-1554

Johnsson JI, Petersson E, Jönsson E, Järvi T, Björnsson BT (1999) Growth hormone-induced effects on mortality, energy status and growth: a field study on brown trout (Salmo trutta). Funct. Ecol. 13: 514-522

Jönsson E, Johnsson JI, Björnsson BT (1996) Growth hormone increases predation exposure of rainbow trout. $P$. Roy. Soc. B - Biol. Sci. 263: 647-651

Kapuscinski AR, Hard JJ, Paulson KM, Neira R, Ponniah A, Kamonrat W, Mwanja W, Fleming IA, Gallardo J, Devlin RH, Trisak J (2007) Approaches to assessing gene flow. In Kapuscinski AR, Hayes KR, Li S, Dana G, eds, Environmental Risk Assessment of Genetically Modified Organisms, Volume 3: Methodologies for Transgenic Fish, CAB International, Oxfordshire, UK, pp 112-150

Kent ML, Whipps CM, Matthews JL, Florio D, Watral V, Bishop-Stewart JK, Poort M, Bermudez L (2004) Mycobacteriosis in zebrafish (Danio rerio) research facilities. Comp. Biochem. Physiol. C Toxicol. Pharmacol. 138: 383390

Kimura M, Ohta T (1969) The average number of generations until extinction of an individual mutant gene in a finite population. Genetics 63: 701-709

Kruer TL, Peck SL, Hostetler HA, Devlin RH, Muir WM (2002) Efficacy of the salmon metallothionein promoter driving expression of the Pacific salmon growth hormone gene (pOnMTGH1) for growth promotion in Japanese medaka (Oryzias latipes). Trans. Res. 11: 83 [abstract]

McGinnity P, Prodöhl P, Ferguson A, Hynes R, Maoiléidigh N, Baker N, Cotter D, O'Hea B, Cooke D, Rogan G (2003) Fitness reduction and potential extinction of wild populations of Atlantic salmon, Salmo salar, as a result of interactions with escaped farm salmon. P. Roy. Soc. B - Biol. Sci. 270: 2443-2450

Miller LM, Kapuscinski AR (1996) Microsatellite DNA markers reveal new levels of genetic variation in northern pike. T. Am. Fish. Soc. 125: 971-977

Muir WM, Howard RD (1999) Possible ecological risks of transgenic organism release when transgenes affect mating success: sexual selection and the Trojan gene hypothesis. P. Natl. Acad. Sci. 96: 13853-13856

Muir WM, Howard RD (2001) Fitness components and ecological risk of transgenic release: a model using Japanese medaka (Oryzias latipes). Am. Nat. 158: 1-16 
National Research Council (2002) Animal Biotechnology: Science-Based Concerns. National Academies Press, Washington, DC

National Research Council (2004) Biological Confinement of Genetically Engineered Organisms. National Academies Press, Washington, DC

National Research Council (2008) Genetically Engineered Organisms, Wildlife, and Habitat: A Workshop Summary. National Academy of Sciences, Washington, DC

Naylor RL, Hindar K, Fleming IA, Goldburg RJ, Williams S, Volpe J, Whoriskey FG, Eagle J, Kelso DDT, Mangel M (2005) Fugitive salmon: assessing the risks of escaped fish from net-pen aquaculture. BioScience 55: 427-437

Ozato K, Kondoh H, Inohara H, Iwamatsu T, Wakamatsu Y, Okada TS (1986) Production of transgenic fish: introduction and expression of chicken $\delta$-crystallin gene in medaka embryos. Cell Differ. Dev. 19: 237-244

R Development Core Team (2008) R: A language and environment for statistical computing. R Foundation for Statistical Computing. http://www.R-project.org

Sakai AK, Allendorf FW, Holt JS, Lodge DM, Molofsky J, Baughman S, Cabin RJ, Cohen JE, Ellstrand NC, McCauley DE (2001) The population biology of invasive species. Annu. Rev. Ecol. Syst. 32: 305-332
Sarkar D (2008) lattice: Lattice Graphics. R package version $0.17-17$

Shima A, Mitani H (2004) Medaka as a research organism: past, present and future. Mech. Develop. 121: 599-604

Sundström LF, Devlin RH, Johnsson JI, Biagi CA (2003) Vertical position reflects increased feeding motivation in growth hormone transgenic coho salmon (Oncorhynchus kisutch). Ethology 109: 701-712

Uematsu K (1990) An analysis of sufficient stimuli for the oviposition in the medaka Oryzias latipes. Journal of the Faculty of Applied Biological Science, Hiroshima University 29: $109-116$

Vila-Gispert A, Alcaraz C, Garcia-Berthou E (2005) Lifehistory traits of invasive fish in small Mediterranean streams. Biol. Invasions 7: 107-116

Whipps CM, Dougan ST, Kent ML (2007) Mycobacterium haemophilum infections of zebrafish (Danio rerio) in research facilities. FEMS Microbiol. Lett. 270: 21-26

Wittbrodt J, Shima A, Schartl M (2002) Medaka - a model organism from the Far East. Nat. Rev. Genet. 3: 53-64

Yamamoto T (1975) Medaka (killifish): biology and strains. Keigaku, Tokyo 